\title{
Hazard quotient profiles used as a risk assessment tool for PFOS and PFOA serum levels in three distinctive European populations
}

\author{
Jan K. Ludwicki a,* , Katarzyna Góralczyk ${ }^{\text {a }}$, Paweł Struciński a , Bogdan Wojtyniak ${ }^{\text {b }}$, Daniel Rabczenko ${ }^{\text {, }}$, \\ Gunnar Toft ${ }^{c}$, Christian H. Lindh ${ }^{\mathrm{d}}$, Bo A.G. Jönsson ${ }^{\mathrm{d}}$, Virissa Lenters ${ }^{\mathrm{e}}$, Dick Heederik ${ }^{\mathrm{e}}$, Katarzyna Czaja ${ }^{\mathrm{a}}$, \\ Agnieszka Hernik ${ }^{\mathrm{a}}$, Henning S. Pedersen ${ }^{\mathrm{f}}$, Valentyna Zvyezday ${ }^{\mathrm{g}}$, Jens Peter Bonde ${ }^{\mathrm{h}}$ \\ ${ }^{a}$ Department of Toxicology and Risk Assessment, National Institute of Public Health - National Institute of Hygiene, Chocimska 24, 00-791 Warsaw, Poland \\ ${ }^{\mathrm{b}}$ Centre of Monitoring and Analyses of Population Health, National Institute of Public Health - National Institute of Hygiene, Chocimska 24, 00-791 Warsaw, Poland \\ ${ }^{c}$ Danish Ramazzini Centre, Department of Occupational Medicine, Aarhus University Hospital, Nørrebrogade 44, Building 2c, 8000 Aarhus C, Denmark \\ d Division of Occupational and Environmental Medicine, Lund University, S-221 85 Lund, Sweden \\ e Division of Environmental Epidemiology, Institute for Risk Assessment Sciences, Utrecht University, P.O. Box 80.178, 3508 TD Utrecht, The Netherlands \\ ${ }^{\mathrm{f}}$ Primary Health Care Clinic, Postbox 570, DK-3900 Nuuk, Greenland \\ ${ }^{\mathrm{g}}$ Department of Social Medicine and Organization of Public Health, Kharkiv National Medical University, 61022 Kharkiv, Ukraine \\ ${ }^{\mathrm{h}}$ Department of Occupational and Environmental Medicine, Copenhagen University Hospital, Bispebjerg Bakke 23, 2400 Copenhagen NV, Denmark
}

\section{A R T I C L E I N F O}

\section{Article history:}

Received 15 May 2014

Accepted 2 October 2014

Available online 21 October 2014

\section{Keywords:}

Perfluorooctane sulfonate

Perfluorooctanoic acid

Hazard quotients

Serum levels

Risk assessment

Environmental contaminants

\begin{abstract}
A B S T R A C T
Perfluorooctane sulfonate (PFOS) and perfluorooctanoic acid (PFOA) blood levels are commonly used as biomarkers of human environmental exposure to these compounds. Many biomonitoring studies indicate $100 \%$ detection for PFOS and PFOA thus justifying a concern of possible risk for the most exposed individuals.

This study addresses the predictive value of hazard quotients (HQs) calculated on the basis of serum PFOS and PFOA in male and female populations of reproductive age in Greenland, Poland and Ukraine.

Overall, 2026 results of PFOS and PFOA serum concentrations (589 males, 1437 females) were obtained from the INUENDO database. HQs were calculated from the actual biomonitoring results and literature-based animal data linking toxicological outcomes and critical PFOS/PFOA serum levels. HQs for serum PFOS were calculated based on Points of Departure (PoD) at $13 \mu \mathrm{gL}^{-1}$ (cynomolgus monkeys, 183 days, changes in THS and $\mathrm{T}_{3}$ ) and for PFOA at $7.1 \mu \mathrm{g} \mathrm{mL}{ }^{-1}$ serum (male rats, 90 days, hepatocellular necrosis, increased liver weight). Uncertainty factors were applied to reflect interspecies differences and human variability. Serum HQs were expressed as a ratio relative to the point of departure for each PFOS and PFOA. Only in the three cases of males in Greenland were there serum PFOS levels showing HQ values exceeding 1, so indicating that such serum levels may be of concern. The mean serum concentration of PFOS was significantly higher in male than in female populations. Despite significant differences between HQ profiles for PFOS and PFOA in donors from Greenland, Poland and Ukraine, the concentrations of these perfluoroalkylated compounds do not indicate a cause for concern, except for the three aforementioned cases from Greenland.

This study demonstrates that the HQ approach can help to interpret human biomonitoring data and thus serve as a valuable tool in further risk assessment priority settings and may also be used as a basis for taking decisions in risk management.
\end{abstract}

(c) 2014 Elsevier Ltd. All rights reserved.

\footnotetext{
* Corresponding author. Tel.: +48 225421328; fax: + 48228497441 .

E-mail addresses: k.ludwicki@pzh.gov.pl (J.K. Ludwicki),kgoralczyk@pzh.gov.pl (K. Góralczyk), pstrucinski@pzh.gov.pl (P. Struciński), bogdan@pzh.gov.pl (B. Wojtyniak), daniel@pzh.gov.pl (D. Rabczenko), gunntoft@rm.dk (G. Toft), Christian.Lindh@med.lu.se (C.H. Lindh), bo_a.jonsson@med.lu.se (B.A.G. Jönsson), V.C.Lenters@uu.nl (V. Lenters), D.Heederik@uu.nl (D. Heederik), kczaja@pzh.gov.pl (K. Czaja), ahernik@pzh.gov.pl (A. Hernik), HSP@MIL.AU.DK (H.S. Pedersen), dmusic@ic.kharkov.ua (V.Zvyezday), Jens.Peter.Ellekilde.Bonde@regionh.dk (J.P. Bonde).
}

\section{Introduction}

Perfluoroalkyl substances (PFASs) belong to a vast group of chemicals which are present in a range of consumer products such as nonionic surfactants and water and oil repellents. The most extensively studied, from the older generation of PFASs, are perfluorooctane sulfonate (PFOS) and perfluorooctanoic acid (PFOA). PFOS and PFOA are not metabolised in mammals (Stahl et al., 2011) and they tend to accumulate when repeatedly administered to experimental animals (Seacat et al., 2003). Environmental and toxicological aspects, including exposure assessment to perfluorinated compounds, have been comprehensively discussed 
(D'eon and Mabury, 2011; Houde et al., 2011; Kucharska et al., 2011; Lau et al., 2007; Olsen et al., 2005; Shin et al., 2011; Stahl et al., 2011).

Olsen et al. (2007) reported both arithmetic and geometric mean half-lives of serum elimination, as being 5.4 years [95\% confidence interval $(\mathrm{CI}), 3.9-6.9]$ and 4.8 years (95\% CI, 4.0-5.8) for PFOS and 3.8 years $(95 \% \mathrm{CI}, 3.1-4.4)$ and 3.5 years $(95 \% \mathrm{CI}, 3.0-4.1)$ for PFOA respectively. Bartell et al. (2010) presented a lower median half-life for PFOA, of 2.3 years (95\% CI, 2.1-2.4 years).

Numerous PFOS and PFOA biomonitoring studies have shown differences in the exposure to these compounds expressed as serum levels ranging from about $10 \mathrm{ng} \mathrm{mL}^{-1}$ in different populations worldwide (Hansen et al., 2001; Harada and Kozumi, 2009; Lau et al., 2007; Lindh et al., 2012; Liu et al., 2012; Struciński et al., 2006; Vassiliadou et al., 2010) to approximately $2 \mu \mathrm{g} \mathrm{mL}^{-1}$, with the highest PFOS concentration of $9.93 \mu \mathrm{g} \mathrm{mL} \mathrm{m}^{-1}$ recorded in occupationally exposed production workers (Olsen et al., 1999). Most of these studies usually report PFOS and PFOA serum levels so as to provide data from various general populations on the overall exposure to a cocktail of anthropogenic chemicals present in the environment or in studying the relationship between exposure and biological response in order to evaluate human health hazards (Liu et al., 2012).

Although blood levels of PFOS and PFOA appeared to have peaked in the 1990s in the USA (Kato et al., 2011; Olsen et al., 2012) and in Sweden (Axmon et al., 2014), their toxicological relevance may still be of concern because of their persistence and long-half-lives (Olsen et al., 2007).

Toxicological outcomes resulting from exposing experimental animals to perfluoroalkylated compounds were summarised by Lau et al. (2007) who showed PFOS to be associated with liver enlargement in rodents and nonhuman primates and PFOA inducing hepatocellular adenomas in rats. The issue of whether toxicological PFOS and PFOA concentrations are relevant in humans remains open, and many biomonitoring studies indeed show that the highest serum levels justify concern of increased risk for most exposed individuals within the studied populations. One possible approach is to estimate the potential risk by comparing actual serum levels with reference serum levels which are observed at points of departure (PoDs). PoDs are used for deriving exposure guidance values such as the reference dose (RfD) or tolerable daily intake (TDI), and are, as an example, associated with no-observableadverse-effect-level (NOAEL) or benchmark dose (BMD) levels for relevant (toxicological) health endpoints (Kirman et al., 2011). Such levels may be regarded as corresponding to a critical change in response arising from exposure to these compounds. In the case of PFOS and PFOA, one of the major difficulties, when undertaking such an approach, is the lack of human epidemiological data clearly indicating a PoD for a given biological response that could be attributed to such serum levels of these compounds. In these instances, animal studies may be used to indicate a PoD for a specific toxicological outcome. The use of PoDs was comprehensively discussed by Aylward and Hays (2011) regarding an interpretation of hexabromocyclododecane biomonitoring data. Brain et al. (2006) used the HQ approach for assessing pharmaceuticals' effects in an aquatic environment. This approach is based on the biomonitoring equivalents (BEs) which is a generally recognised concept used for interpreting biomonitoring data. A comprehensive and detailed review of the interrelationships between BEs and HQs was presented by Aylward et al. (2013). Moreover, Borg et al. (2013) used HQs for cumulative risk assessment of 17 perfluoroalkylated substances in a Swedish population and showed that there was no concern for hepatotoxicity and reproductive toxicity in the general population. However, they pointed out that high local exposures for individuals may be of concern. The mean serum levels do not necessarily describe individual risks that may be a source of concern. For example, results presented by Holmström et al. (2005) indicate that although the mean PFOS concentration was $36 \mathrm{ng} \mathrm{mL}^{-1}$, the individual PFOS levels ranged from 6.0 to $130 \mathrm{ng} \mathrm{mL} \mathrm{m}^{-1}$ in serum, thus presenting an over twenty-fold difference between the lowest and the highest results within the studied population and 3.6-fold difference between the mean and the highest concentration of PFOS. Thus using mean values may ignore a possible risk for individuals at the high end of the exposure distribution.

The crucial step for risk characterisation based on biomonitoring is to link PFOS and PFOA serum levels with toxicological endpoints. Although there are many toxicological studies on the biological response following exposure of experimental animals to PFOS (Austin et al., 2003; Chang et al., 2008), only a few link serum levels with biological effects. Such a study was performed by Seacat et al. (2002) on cynomolgus monkeys and has been recognised by EFSA (2008) as being appropriate to derive a $\mathrm{BMD}_{10}$. Similarly, among numerous animal studies on PFOA, Perkins et al. (2004) observed hepatocellular hypertrophy and increased liver weight following dietary exposure of rats to PFOA. These were recognised by EFSA (2008) as being relevant to derive the NOAEL.

The lowest serum levels corresponding to specific toxic outcomes may be used to derive the relevant BEs. These can be defined as a concentration of a chemical in blood or other medium that corresponds to allowable exposure guidance values i.e. RfD or TDI (Hays et al., 2008) thus representing a PoD. HQs may be calculated using human or animal data (Hays et al., 2007, 2008), nevertheless in instances when the HQ is derived from animal data, the appropriate uncertainty factors (UFs) should be included in the calculation.

This study was undertaken to address and discuss the predictive value of HQs for assessing the risks resulting from individual nonoccupational exposures to PFOS and PFOA. We report profiles of individual risks, expressed as HQs, calculated from actual and critical PFOS and PFOA serum levels in men and women from Greenland, Poland and Ukraine.

\section{Methods}

\subsection{Ethics}

The study was officially approved by the following local ethical committees: Polish Bioethical Committee (approval no. 6/2002 of 3.07.2002), Ethical Committee for Human Research in Greenland (approval no. 2010-13) and the Commission on Ethics and Bioethics of Kharkiv National Medical University in Ukraine (protocol number 7, October 7 2009). All participating couples signed informed consent forms.

\subsection{Study population}

The study population consisted of pregnant women and their male partners from Greenland, Poland and Ukraine, and has been earlier described in detail (Toft et al., 2005) as constituting the INUENDO cohort. Couples were recruited from 15 municipalities and 4 settlements representing Inuits from all regions of Greenland, during their visits to obstetric outpatient clinics of the Gynaecological and Obstetric Hospital (Warsaw, Poland), and in eight antenatal clinics in three maternity hospitals in Kharkiv, Ukraine. For the PFOS and PFOA analysis, 2026 blood samples (589 males and 1437 females) were taken from the INUENDO biobank. The difference between the number of males recruited to the study and male blood donors have been explained by Bonde et al. (2008).

\subsection{Sample collection}

A uniform procedure was used to collect all serum samples. Blood was drawn from the cubital vein into $10 \mathrm{~mL}$ vacuum tubes for serum collection without additives (Becton Dickinson, Meylan, France) and centrifuged at $4000 \mathrm{~g}$ for $15 \mathrm{~min}$ at room temperature. The serum supernatant was then transferred using ethanol rinsed Pasteur pipettes into ethanol rinsed brown glass bottles (Termometerfabriken, Gothenburg, Sweden). A piece of aluminium foil was placed on top of the bottles 
which were then sealed. All sampling devices were prepared and sent from Lund University, Sweden to Greenland, Poland and Ukraine.

The detailed procedure, including temperature regime and further sample handling are described elsewhere (Jönsson et al., 2005).

\subsection{PFOS and PFOA analyses}

This was performed by LC/MS/MS at the Division of Occupational and Environmental Medicine, Department of Laboratory Medicine, Lund University, Sweden. To $100 \mu \mathrm{L}$ of test serum, the following were added; $10 \mu \mathrm{L}$ glucuronidase, $10 \mu \mathrm{L}$ ammonium acetate buffer, $10 \mu \mathrm{L}$ methylumbelliferyl- $\beta$-D-glucuronide and $25 \mu \mathrm{L}$ of water:acetonitrile (50:50) solution containing ${ }^{13} \mathrm{C}$ - or ${ }^{18} \mathrm{O}$-labelled internal standards for all evaluated compounds. The mixture was then kept at $37{ }^{\circ} \mathrm{C}$ and $90 \mathrm{~min}$ for the reaction to occur after which proteins were precipitated by adding $175 \mu \mathrm{L}$ acetonitrile followed by vigorous shaking for $30 \mathrm{~min}$. The samples were thereafter centrifuged at $4200 \mathrm{~g}$ and $3 \mu \mathrm{L}$ of the supernatant was injected onto a LC/MS/MS (UFLC ${ }^{\mathrm{XR}}$, SHIMADZU Corporation, Kyoto, Japan), using hybrid quadrupole linear ion trap mass spectrometry equipped with a Turbolon-Spray source (QTRAP 5500, Applied Biosystems). Measurement quality was assured by analysing sample blanks and in-house quality control samples, prepared from a large volume of serum spiked with small amounts of PFASs. The detailed analytical procedure, including equipment, analytical parameters and quality assurance has been described by Lindh et al. (2012).

\subsection{Critical PFOS and PFOA levels used as PoDs}

Although there are numerous toxicological data on PFOS and PFOA animal exposures (Stahl et al., 2011), only few are linked to a toxicological response with serum levels. Animal data allowing the determination of critical serum levels for PFOS were generated by Seacat et al. (2002) following long-term dietary studies on cynomolgus monkeys. In this study altered hormone and cholesterol levels were observed at PFOS serum levels that were regarded as being critical according to scientific opinion issued by the European Food Safety Authority (EFSA, 2008) who concluded that $0.03 \mathrm{mg}$ ( $\mathrm{kg} \mathrm{BW} \mathrm{day})^{-1}$, corresponding to $13 \mu \mathrm{g} \mathrm{mL}{ }^{-1}$, should be used as the NOAEL. We considered these studies as most relevant because the above endpoints were generated from chronic exposure of primates.

Butenhoff et al. (2002) observed increased liver weight in primates following three months of oral exposure to PFOA, which was partly due to hepatocellular hypertrophy. The authors however, made no suggestions about any possible relationship between serum levels and this outcome.

We therefore used animal data reported by Perkins et al. (2004) on the hepatocellular hypertrophy and increased liver weight following 90 days dietary exposure in rats. This data were also used by EFSA to propose a NOAEL $=0.06 \mathrm{mg}(\mathrm{kg} \mathrm{BW} \text { day })^{-1}$ which corresponded to a critical serum level of $7.1 \pm 1.15 \mu \mathrm{g} \mathrm{mL}{ }^{-1}$ (EFSA, 2008) regarded as the PoD in our study. EFSA addressed the fact that the lowestobservable-adverse-effect-level (LOAEL) for changes in hepatocytes in other rat studies was considerably lower in males, thus providing an additional margin of safety (MoS) to risk evaluation. This data is summarised in Table 1.

\subsection{Hazard quotients (HQs)}

Numerous biomonitoring studies have measured concentrations of these chemicals in biological specimens like blood, urine, adipose tissue, and breast milk. To assess the biological relevance of these findings, different approaches have been extensively discussed by Hays et al. (2008) and Becker et al. (2012). Normally, for a biomonitoring-based risk assessment, the actual exposures to chemicals are compared with the exposure at the relevant PoD which, for the purpose of interpretation of biomonitoring results, can be defined as an internal exposure-response point that marks the threshold above which the incidence begins to increase, thus allowing biomonitoring data to be placed within a public health risk context (Hays et al., 2008). This approach also takes into account the fact that the internal exposure, expressed as serum concentrations above PoD, as being of concern. Another method considers that the presence of the monitored chemicals in body fluids may be assumed as the internal exposure to these compounds thus leads to the concept of HQs and provides a window on internal doses arising from external chemical exposures (Aylward et al., 2011). Since PoD derived NOAEL or BMD are based on animal experiments, the generally accepted default $\mathrm{UF}=100$ (i.e. $10 \times$ for inter-species interpolation and $10 \times$ for human variability) are used according to the formula:

Hazard quotient $(\mathrm{HQ})=\frac{\text { Actual serum level } \times \mathrm{UF}}{\text { Serum level at PoD }}$,

thus implying that HQs below 1 indicate an absence of risk for the particular endpoint considered, whereas HQs greater than 1 indicate exposure that may be regarded as being of concern.

(Safe) $1>\mathrm{HQ}>1$ (unsafe).

\subsection{Statistics}

The R 3.0.1 statistical software (R Core Team, 2013) was used for all calculations and graphics. The differences between hazard quotient profiles for PFOS and PFOA were subjected to the non-parametric analysis of variance by the Kruskal-Wallis test followed by Mann-Whitney tests for localising the differences. Spearman rank correlation coefficients were calculated between PFOS and PFOA data and the paired Wilcoxon test was used for analysing the differences between PFOS and PFOA concentrations in male and female sera. For all analyses the level of significance was set at 0.05 .

\section{Results}

Summary statistics for serum PFOS and PFOA concentrations in Greenland, Poland and Ukraine are presented in Table 2.

Fig. 1 presents density functions of HQ profiles for individual PFOS and PFOA. These demonstrate the most probable HQ ranges for males and females in population from Greenland, Poland and Ukraine.

Fig. 1 shows that $100 \%$ of HQs for PFOA were concentrated within a low range, far from ever reaching the value of 1 , which was best illustrated in the sera from Ukrainian donors, where the distribution curves were very leptokurtic. This confirms that the internal exposure to PFOA

Table 1

Endpoints and PoDs used for this study.

\begin{tabular}{|c|c|c|c|c|}
\hline Substance & Exposure details & $\begin{array}{l}\text { Critical (reference) } \\
\text { serum level (PoD) }\end{array}$ & Endpoint & Reference \\
\hline PFOS & Cynomolgus monkeys 183 days, with diet & $13 \mu \mathrm{g} \mathrm{mL}^{-1}\left(\mathrm{BMD}_{10}\right)$ & $\begin{array}{l}\text { Increased TSH }(M) \text {, reduced } T_{3}(M, F) \text {, } \\
\text { HDL }(F)\end{array}$ & Seacat et al. (2002); EFSA (2008) \\
\hline PFOA & Rats 90 days, with diet & $7.1 \pm 1.15 \mu \mathrm{g} \mathrm{mL}^{-1}(\mathrm{NOAEL})$ & $\begin{array}{l}\text { Hepatocellular necrosis and increased } \\
\text { liver weight }(\mathrm{M})\end{array}$ & Perkins et al. (2004); EFSA (2008) \\
\hline
\end{tabular}


Table 2

Summary statistics for PFOS and PFOA serum levels ( $\mathrm{ng} \mathrm{mL} \mathrm{m}^{-1}$ ), by sex and country.

\begin{tabular}{|c|c|c|c|c|c|c|c|c|c|c|c|}
\hline Sex & PFAS & Country & $\mathrm{N}$ & Mean & SD & Min & Max & Median & QI & QIII & P95 \\
\hline \multirow[t]{8}{*}{ Males } & \multirow[t]{4}{*}{ PFOS } & Greenland & 196 & 51.9 & 24.4 & 12.3 & 160.6 & 44.7 & 35.6 & 60.6 & 98.1 \\
\hline & & Poland & 190 & 18.6 & 5.7 & 8.2 & 40.2 & 18.5 & 14.4 & 22.1 & 29.1 \\
\hline & & Ukraine & 203 & 8.1 & 4.0 & 2.8 & 29.9 & 7.6 & 5.4 & 9.8 & 14.1 \\
\hline & & Total & 589 & 26 & 23.8 & 2.8 & 160.6 & 18.4 & 9.1 & 35.6 & 72.8 \\
\hline & \multirow[t]{4}{*}{ PFOA } & Greenland & 196 & 4.8 & 1.6 & 1.5 & 13.7 & 4.5 & 3.8 & 5.5 & 7.3 \\
\hline & & Poland & 190 & 5.3 & 2.1 & 1.5 & 16.0 & 4.8 & 3.7 & 6.3 & 9.0 \\
\hline & & Ukraine & 203 & 1.8 & 2.8 & 0.2 & 35.0 & 1.3 & 1.0 & 1.8 & 3.7 \\
\hline & & Total & 589 & 3.9 & 2.7 & 0.2 & 35.0 & 3.8 & 1.7 & 5.3 & 8.3 \\
\hline \multirow[t]{8}{*}{ Females } & \multirow[t]{4}{*}{ PFOS } & Greenland & 572 & 22.9 & 12.1 & 4.1 & 87.3 & 20.2 & 15.5 & 26.0 & 49.5 \\
\hline & & Poland & 259 & 8.4 & 2.9 & 1.6 & 21.3 & 8.0 & 6.5 & 10.2 & 13.4 \\
\hline & & Ukraine & 606 & 5.3 & 2.3 & 0.7 & 18.1 & 5.0 & 3.7 & 6.4 & 9.4 \\
\hline & & Total & 1437 & 12.9 & 11.4 & 0.7 & 87.3 & 8.5 & 5.3 & 17.5 & 31.7 \\
\hline & \multirow[t]{4}{*}{ PFOA } & Greenland & 572 & 2.0 & 0.8 & 0.5 & 5.1 & 1.8 & 1.3 & 2.5 & 3.6 \\
\hline & & Poland & 259 & 2.8 & 1.3 & 0.5 & 9.8 & 2.7 & 1.9 & 3.5 & 4.9 \\
\hline & & Ukraine & 606 & 1.1 & 0.7 & 0.2 & 9.8 & 0.9 & 0.7 & 1.3 & 2.1 \\
\hline & & Total & 1437 & 1.8 & 1.1 & 0.2 & 9.8 & 1.5 & 1.0 & 2.3 & 3.8 \\
\hline
\end{tabular}

QI - first quartile, QIII - third quartile, P95 - 95 percentile point.

should not be recognised as being of concern in the populations under study. The HQ profiles for PFOS had similar shapes, however they were more right-skewed, even exceeding the value of 1 in the sera of three Inuit males. As expected, the shape of the distribution curve demonstrates that a considerable part of Inuit males have been exposed to PFOS to a greater extent than the other studied populations.

Significant differences were also found between HQ profiles for PFOS and PFOA in the donors from Greenland, Poland and Ukraine according to the Kruskal-Wallis test and subsequent Mann-Whitney testing ( $p<0.0001$ ), thus indicating that exposure patterns in these three countries may be different. The paired Wilcoxon test also demonstrated significant differences $(\mathrm{p}<0.001)$ in mean serum PFOS and PFOA concentrations between male and female donors, regardless of the country of origin.

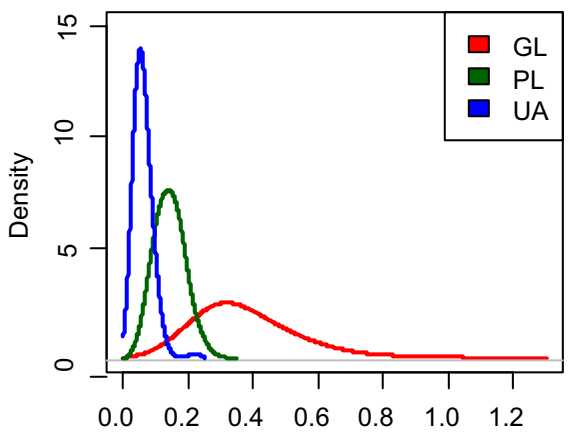

HQs for PFOS in Males; GL - Greenland. $\mathrm{PL}$ - Poland, UA - Ukraine

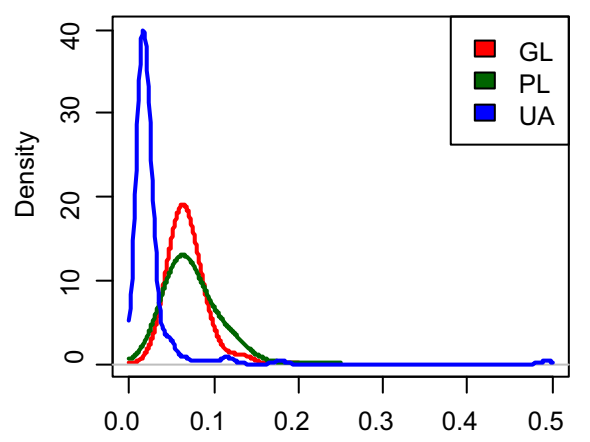

HQs for PFOA in Males; GL - Greenland. $\mathrm{PL}$ - Poland, UA - Ukraine
In order to assess possible relationships between individual concentrations of PFOS and PFOA, Spearman rank correlation coefficients were determined, where Table 3 shows a positive correlation between serum levels of both compounds in all of the tested populations.

Fig. 2 graphically presents individual results in the form of scatterplots of HQs for PFOS and PFOA, by sex and country.

\section{Discussion}

The present study has attempted to show that biomonitoring risk profiles can be determined on test populations from Greenland, Poland and Ukraine in terms of HQs for PFOS and PFOA. A similar approach was undertaken by Borg et al. (2013) who used individual HQs for hepatotoxicity and reproductive effects for 17 perfluoroalkylated
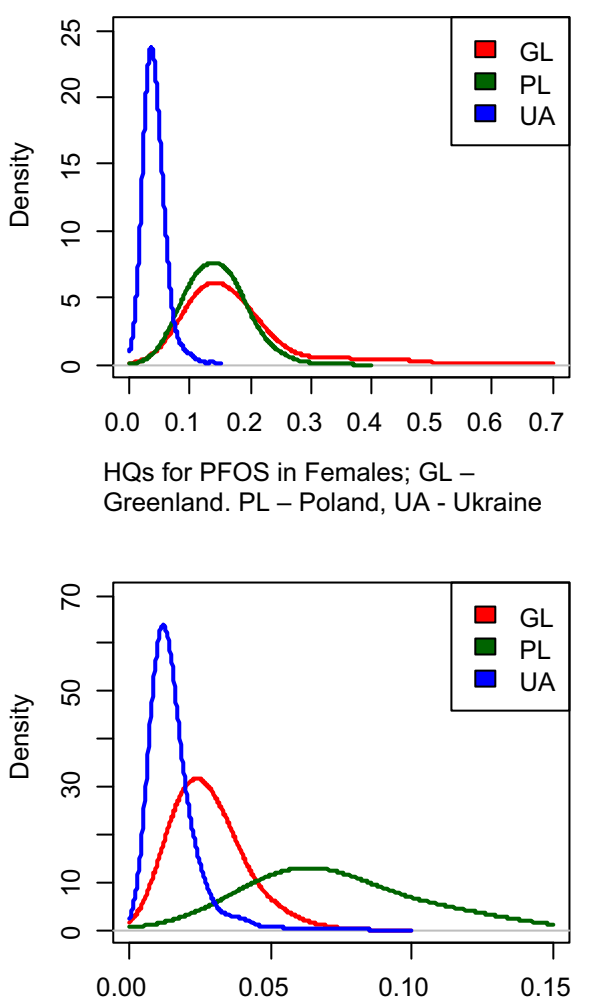

HQs for PFOA in Females; GL Greenland. PL - Poland, UA - Ukraine

Fig. 1. HQ density functions for PFOS and PFOA. 
Table 3

Spearman rank correlation coefficients between PFOS and PFOA in males and females, by country.

\begin{tabular}{lll}
\hline & & Rho $^{*}$ \\
\hline Males & Greenland & 0.415 \\
& Poland & 0.343 \\
\multirow{3}{*}{ Females } & Ukraine & 0.561 \\
& Greenland & 0.495 \\
& Poland & 0.550 \\
& Ukraine & 0.509 \\
\hline
\end{tabular}

* $\mathrm{p}<0.001$.

and polyfluoroalkylated substances in order to derive the relevant hazard indexes (HI) in a Swedish population. Borg et al. (2013) proposed the same PoD for hepatotoxicity following exposure to PFOA ( $7.1 \mu \mathrm{g} \mathrm{mL} \mathrm{L}^{-1}$ ) as was used in the present study. For PFOS hepatotoxicity the former study proposed a PoD $=4.04 \mu \mathrm{g} \mathrm{mL}{ }^{-1}$, however it was not clearly stated which animal study was used as reference. For PFOS we used a PoD $=13 \mu \mathrm{g} \mathrm{mL}{ }^{-1}$ which we considered this as being advantageous since it was derived from a primates' study. It is however clear that any hazard assessments based on HQs depend on PoDs derived from animal studies for different endpoints, thereby leading to considerable variation. For example Borg et al. (2013) presented HQs $>1$ for PFOS immunotoxicity and PFOA mammary gland development equal to 229 and 18 , respectively.

Our study has demonstrated that the HQ profile shapes for PFOS and PFOA prove that internal exposure to these compounds is at least one order of magnitude below the levels that may be of concern in most of the studied populations. Serum concentrations in present studies are similar to those presented and discussed in Greek donors by Vassiliadou et al. (2010), who found that the highest PFOS blood concentration was $30.36 \mathrm{ng} \mathrm{mL} \mathrm{m}^{-1}$, similar to our findings in Ukraine (29.9 $\left.\mathrm{ng} \mathrm{mL}^{-1}\right)$, slightly lower than in Poland $\left(40.2 \mathrm{ng} \mathrm{mL}^{-1}\right.$ ) and much lower than in Greenland (160.6 $\mathrm{ng} \mathrm{mL}^{-1}$ ). However, even the highest level found in our study was 13.6 times lower than the mean serum level reported by Olsen et al. (1999) in occupationally exposed workers. It should also be noted that the decreasing time trends of PFOS and PFOA serum concentrations between 1987 and 2007 have been observed in Swedish women (Axmon et al., 2014).

The present study has shown that the mean PFOS and PFOA serum concentrations were higher in males than in females in all test populations. Significantly higher serum concentrations were also observed in male donors compared to female donors in Greece (Vassiliadou et al., 2010) and Germany (Midasch et al., 2006). In a multicentre collaborative study (Kannan et al., 2004) markedly higher concentrations in Polish male donors were reported, although in other studied populations there were practically no gender related differences or they were less pronounced. The question of whether exposure to perfluoroalkylated acids presents a risk to human health was comprehensively discussed by Rosen et al. (2009) and still remains open regardless of earlier findings by Olsen et al. (1999), who reported no substantial changes in serum hepatic enzymes, cholesterol or lipoproteins associated with high PFOS serum levels (up to $6000 \mathrm{ng} \mathrm{mL}^{-1}$ ) in occupationally exposed workers. It is therefore obvious, that since the toxic response is a
GL, Males

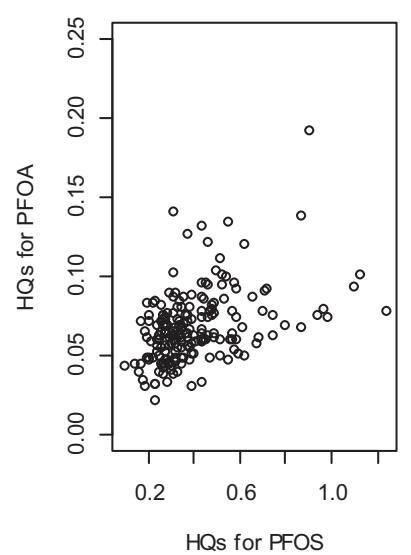

GL, Females

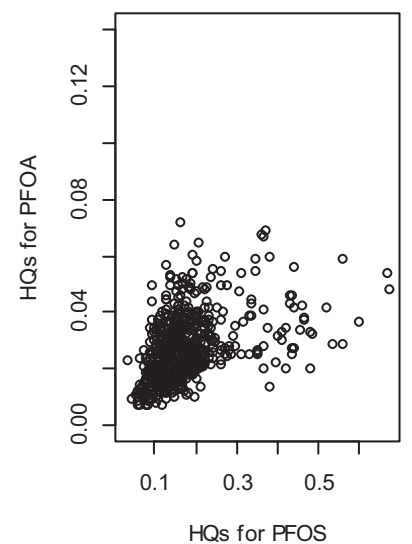

PL, Males

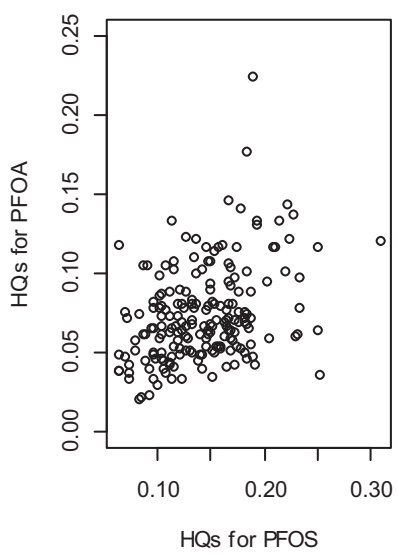

PL, Females

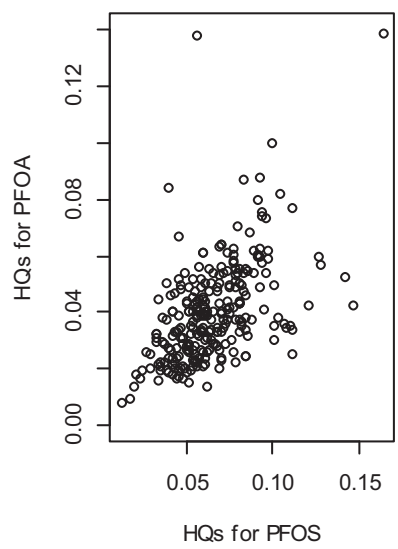

UA, Males*

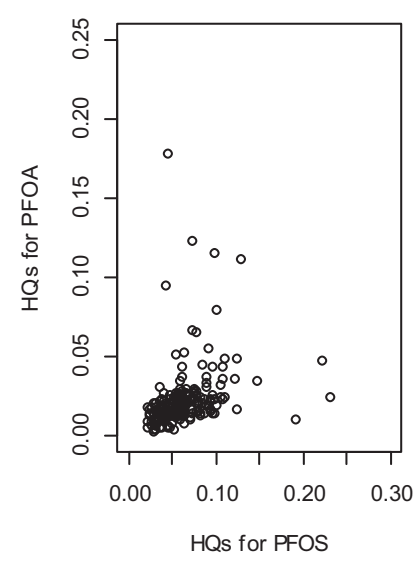

UA, Females

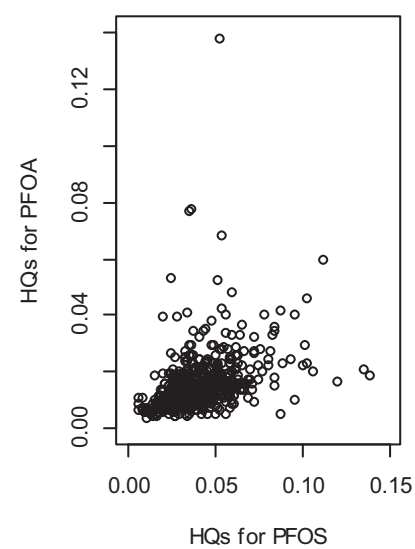

Fig. 2. Scatterplots of HQs for PFOS and PFOA, by sex and country; GL - Greenland, PL - Poland, and UA - Ukraine. 
function of toxicity and exposure, both factors play a role in the risk assessment and even moderately toxic substances may be dangerous, depending on varying circumstances.

It is generally assumed that the default uncertainty factors in worstcase scenarios provide wide safety margins and thus offer adequate protection from toxic effects. However, since safety margins usually derive from toxicological studies based on the exposure of experimental animals to a single substance, the question arises whether they provide the required protection when exposed to a cocktail of numerous chemical pollutants, which is usually the case for environmental exposure (Martin et al., 2013). Moreover, some of these substances may exert the same biological response regardless whether the mechanisms underlying the response are alike or different. Several studies have reviewed aspects of the cumulative risk as defined by the probability of any harmful effect occurring through a common toxic effect associated with concurrent exposure by all routes of exposure to a group of chemicals that share a common mechanism of toxicity (Kostka et al., 2011; Reffstrup et al., 2010; Stephenson et al., 2006) and Sexton (2012) who added a new, socioeconomic dimension to the overall discussion on this issue. It is obvious that the studied populations were environmentally exposed to other chemicals which may participate in any cumulative toxicity due to similar modes of action. Such an assumption leads to the conclusion that a hazard/risk assessment based on exposure to a single compound may not address the 'overall' risk of the toxic response because of an inherent combined exposure to other substances which may contribute to the cumulative toxicity due to similar modes of action.

In contrast, the currently used default uncertainty factors of 100 as applied for deriving toxicological reference values from NOAEL are often regarded as being too conservative and unjustified (Hattis et al., 1987; Renwick, 1991), thus leading to an overestimation of risk.

\section{Conclusions}

All individual HQs for the Inuit, Polish and Ukrainian donors were below 1 except for the three HQs in male donors from Greenland, thus indicating no concern due to PFOS and PFOA exposure. Our results allow the presumption that despite applying rather conservative uncertainty factors, the HQ profiles for PFOS in the Greenland male population show that individual exposures in some cases may be a cause for concern, indicating the need for more in-depth analysis in order to find out possible sources of exposure and thus to propose preventive measures.

The present study thus demonstrates the general usefulness of HQ concept as an effective means to interpret in biomonitoring results within the public health. There is also a need for more toxicological data on other PFAS congeners besides PFOS and PFOA to provide an improved background for any cumulative risk assessment of PFASs.

\section{Conflict of interest statement}

The authors have no financial interest or other conflicts of interest in the publication of these results.

$\begin{array}{ll}\text { Abbreviations used in this paper } \\ \text { BE } & \text { biomonitoring equivalent } \\ \text { BMD } & \text { benchmark dose } \\ \text { EFSA } & \text { European Food Safety Authority } \\ \text { HI } & \text { hazard index } \\ \text { HQ } & \text { hazard quotient } \\ \text { LC } & \text { liquid chromatography } \\ \text { LC/MS/MS liquid chromatography tandem mass spectrometry } \\ \text { LOAEL } & \text { lowest-observable-adverse-effect-level } \\ \text { MoE } & \text { margin of exposure } \\ \text { MoS } & \text { margin of safety } \\ \text { NOAEL } & \text { no-observable-adverse-effect-level } \\ \text { PFASs } & \text { perfluorinated compounds }\end{array}$

PFOA perfluorooctanoic acid

PFOS perfluorooctane sulfonate

PoD point of departure

PPAR- $\alpha$ peroxisome proliferated-activated receptor-alpha

RfD reference dose

UF uncertainty factor

\section{Acknowledgements}

The collection of the serum samples used in this study was part of the project "INUENDO - Biopersistent organochlorines in diet and human fertility. Epidemiological studies of time to pregnancy and semen quality in Inuit and European populations", supported by The European Commission to the 5th Framework Programme Quality of Life and Management of Living Resources, Key Action 4 on Environment and Health (contract no. QLK4-CT-2001-00202), http://www.inuendo. $\mathrm{dk}$. The present study was funded by the project "CLEAR - Climate change, environmental contaminants and reproductive health (grant agreement no. 226217)" supported by the European Commission to the 7th Framework Programme: FP7-ENV-2008-1 environment (including climate change), http://www.inuendo.dk/clear. This work has also been financially supported by the Polish Ministry of Science and Higher Education, decision no. 1315/7.PR UE/2010/7.

\section{References}

Austin ME, Kasturi BS, Barber M, Kannan K, MohanKumar PS, MohanKumar SMJ. Neuroendocrine effects of perfluorooctane sulfonate in rats. Environ Health Perspect 2003; 111:1485-9.

Axmon A, Axelsson J, Jakobsson K, Lindh CH, Jönsson BAG. Time trends between 1987 and 2007 for perfluoroalkyl acids in plasma from Swedish women. Chemosphere 2014; 102:61-7.

Aylward LL, Hays SM. Biomonitoring-based risk assessment for hexabromocyclododecane (HBCD). Int J Hyg Environ Health 2011;214:179-87.

Aylward LL, Becker RA, Kirman CR, Hays SM. Assessment of margin of exposure based on biomarkers in blood: an exploratory analysis. Regul Toxicol Pharmacol 2011;61: $44-52$.

Aylward LL, Kirman KR, Schoeny R, Portier CJ, Hays SM. Evaluation of biomonitoring data from the CDC National Exposure Report in a risk assessment context: perspectives across chemicals. Environ Health Perspect 2013;121:287-94

Bartell SM, Calafat AM, Lyu C, Kato K, Ryan PB, Steenland K. Rate of decline in serum PFOA concentrations after granular activated carbon filtration at two public water systems in Ohio and West Virginia. Environ Health Perspect 2010;118:222-8.

Becker RA, Hays SM, Robinson S, Aylward LL. Development of screening tools for the interpretation of chemical biomonitoring data. J Toxicol 2012. http://dx.doi.org/10. 1155/2012/941082. [Article ID 941082].

Bonde JP, Toft G, Rylandrr L, Rignell-Hydbom A, Giwercman A, Spano M, et al. Fertility and markers of male reproductive function in Inuit and European populations spanning large contrasts in blood levels of persistent organochlorines. Environ Health Perspect 2008;116:269-77.

Borg D, Lund BO, Lindquist NG, Håkansson H. Cumulative health risk assessment of 17 perfluoroalkylated and polyfluoroalkylated substances (PFASs) in the Swedish population. Environ Int 2013;59:112-23.

Brain RA, Sanderson H, Sibley PK, Solomon KR. Probabilistic ecological hazard assessment: evaluating pharmaceutical effects on aquatic higher plants as an example. Ecotoxicol Environ Saf 2006;64:128-35.

Butenhoff J, Costa G, Elcombe C, Farrar D, Hansen K, Iwai H, et al. Toxicity of ammonium perfluorooctanoate in male cynomolgus monkeys after oral dosing for 6 months. Toxicol Sci 2002;69:244-57

Chang S-C, Thibodeaux JR, Eastvold ML, Ehresman DJ, Bjork JA, Froehlich JW, et al. Thyroid hormone status and pituitary function in adult rats given oral doses of perfluorooctanesulfonate (PFOS). Toxicology 2008;243:330-9.

D'eon JC, Mabury SA. Is indirect exposure a significant contributor to the burden of perfluorinated acids observed in humans? Environ Sci Technol 2011:45:7974-84.

EFSA. Perfluorooctane sulfonate (PFOS), perfluorooctanoic acid (PFOA) and their salts. Scientific opinion of the panel on contaminants in the food chain. EFSA J. 2008;653: $1-131$.

Hansen KJ, Clemen LA, Ellefson ME, Johnson HO. Compound-specific, quantitative characterization of organic fluorochemicals in biological matrices. Environ Sci Technol 2001; 35:766-70.

Harada KH, Kozumi A. Environmental and biological monitoring of persistent fluorinated compounds in Japan and their toxicities. Environ Health Prev Med 2009;14:7-19.

Hattis D, Erdreich L, Ballew M. Human variability in susceptibility to toxic chemicals. A preliminary analysis of pharmacokinetic data from normal volunteers. Risk Anal 1987;7:415-26. 
Hays SM, Becker RA, Leung HW, Aylward LL, Pyatt DW. Biomonitoring equivalents: a screening approach for interpreting biomonitoring results from a public health risk perspective. Regul Toxicol Pharmacol 2007;47:96-109.

Hays SM, Aylward LL, LaKind JS, Bartels MJ, Barton HA, Boogaard PJ, et al. Guidelines for the derivation of biomonitoring equivalents: report from the biomonitoring equivalents workshop. Regul Toxicol Pharmacol 2008;51:S4-S15.

Holmström KE, Berglund M, Järnberg U. Exposure to perfluorinated acids in 108 Swedish women in relation to methylmercury and fish consumption. Poster ANA003 "FLUOROS" 9th International Symposium on Fluorinated Alkyl Organics in the Environment. August 2005, Toronto, Canada; 2005. [Available: http://www.chem. utoronto.ca/symposium/fluoros/analytical.htm. Accessed 5 January 2014].

Houde M, De Silva AO, Muir DCG, Lether RJ. Monitoring of perfluorinated compounds in aquatic biota: an updated review. Environ Sci Technol 2011;45:7962-73.

Jönsson BAG, Rylander L, Lindh C, Rignell-Hydbom A, Giwercman A, Toft G, et al. Interpopulation variations in concentrations, determinants of and correlations between 2,2'4,4',5,5'-hexachlorobiphenyl (CB-153) and 1,1-dichloro-2,2-bis ( $p$-chlorophenyl)ethylene (p, $\left.\mathrm{p}^{\prime}-\mathrm{DDE}\right)$ : a cross-sectional study of 3161 men and women from Inuit and European populations. Environ Health 2005;4(27). http://dx.doi.org/10.1186/1476069X-4-27.

Kannan K, Corsolini S, Falandysz J, Fillmann G, Kumar KS, Laganathan BG, et al. Perfluorooctanesulfonate and related fluorochemicals in human blood from several countries. Environ Sci Technol 2004;38:4489-95.

Kato K, Wong L-Y, Jia LT, Kulienyik Z, Calafat AM. Trends in exposure to polyfluoroalkyl chemicals in the U.S. population: 1999-2008. Environ Sci Technol 2011;45:8037-45.

Kirman CR, Aylward LL, Hays SM, Krishnan K, Nong A. Biomonitoring equivalents for DDT/ DDE. Regul Toxicol Pharmacol 2011;60:172-80.

Kostka G, Urbanek-Olejnik K, Liszewska M. Risk assessment for cumulative exposure to pesticide residues in food. Rocz Panstw Zakl Hig 2011;62:127-36. [in Polish].

Kucharska A, Góralczyk K, Czaja K, Struciński P, Hernik A, Korcz W, et al. Ubiquitous perfluorinated compounds. Rocz Panstw Zakl Hig 2011;62:137-44. [in Polish].

Lau C, Anitole K, Hodes C, Lai D, Pfahles-Hutchens A, Seed J. Perfluoroalkyl acids: a review of monitoring and toxicological findings. Toxicol Sci 2007;99:366-94.

Lindh CH, Rylander L, Toft G, Axmon A, Rignell-Hydbom A, Giwercman A, et al. Blood serum concentrations of perfluorinated compounds in men from Greenlandic Inuit and European populations. Chemosphere 2012;88:1269-75.

Liu W, Dong G, Luo Y, Liu L, Cao Z, Li X, et al. Estimation of reference values for PFOS and PFOA in human biomonitoring and relevance of exposure among family members in China. J Environ Prot 2012;3:353-61. http://dx.doi.org/10.4236/jep.2012.34045.

Martin OV, Martin S, Kortenkamp A. Dispelling urban myths about default uncertainty factors in chemical risk assessment - sufficient protection against mixture effects. Environ Health 2013;12:53. http://dx.doi.org/10.1186/1476-069X-12-53.

Midasch O, Schettgen T, Angerer J. Pilot study on the perfluorooctanesulfonate and perfluorooctanoate exposure of the German general population. Int J Hyg Environ Health 2006;209:489-96

Olsen GW, Burris JM, Mandel JH, Zobel LR. Serum perfluorooctane sulfonate and hepatic and lipid clinical chemistry tests in fluorochemical production employees. J Occup Environ Med 1999;41:799-806.
Olsen GW, Huang H-Y, Helzlsouer KJ, Hansen KJ, Butenhoff JL, Mandel JH. Historical comparison of perfluorooctanesulfonate, perfluorooctanoate, and other fluorochemicals in human blood. Environ Health Perspect 2005;113:539-45.

Olsen GW, Burris JM, Ehresman DJ, Froehlich JW, Seacat AM, Butenhoff JL, et al. Half-life of serum elimination of perfluorooctanesulfonate, perfluorohexanesulfonate, and perfluorooctanoate in retired fluorochemical production workers. Environ Health Perspect 2007; 115:1298-305.

Olsen GW, Lange CC, Ellefson ME, Mair DC, Church TR, Goldberg CL et al. Temporal trends of perfluoroalkyl concentrations in American Red Cross adult blood donors. Environ Sci Technol 2012;46:6330-8.

Perkins RG, Butenhoff JL, Kennedy Jr GL, Palazzolo MJ. 13-Week dietary toxicity study of ammonium perfluorooctanoate (APFO) in male rats. Drug Chem Toxicol 2004;27:361-78

R Core Team. R: a language and environment for statistical computing. Vienna, Austria: R Foundation for Statistical Computing; 2013 [Available: http://www.R-project.org/].

Reffstrup TK, Larsen JC, Meyer O. Risk assessment of mixtures of pesticides. Current approaches and future strategies. Regul Toxicol Pharmacol 2010;56:174-92.

Renwick AG. Safety factors and establishment of acceptable daily intakes. Food Addit Contam 1991;8:135-49.

Rosen MB, Lau C, Corton JC. Does exposure to perfluoroalkyl acids present a risk to human health? Toxicol Sci 2009;111:1-3.

Seacat AM, Thomford PJ, Hansen KJ, Olsen GA, Case MT, Butenhoff JL. Subchronic toxicity studies on perfluorooctanesulfonate potassium salt in cynomolgus monkeys. Toxicol Sci 2002;68:249-64.

Seacat AM, Thomford PJ, Hansen KJ, Clemen LA, Eldridge SR, Elcombe CR, et al. Subchronic dietary toxicity of potassium perfluorooctanesulfonate in rats. Toxicology 2003;183:117-31.

Sexton K. Cumulative risk assessment: an overview of methodological approaches for evaluating combined health effects from exposure to multiple environmental stressors. Int J Environ Res Public Health 2012:9:370-90. http://dx.doi.org/10.3390/ijerph9020370.

Shin H-M, Vieira VM, Ryan B, Steenland K, Bartell SM. Retrospective exposure estimation and predicted versus observed serum perfluorooctanoic acid concentrations for participants in the C8 health project. Environ Health Perspect 2011;119:1760-5.

Stahl T, Mattern D, Brunn H. Toxicology of perfluorinated compounds. Environ Sci Eur 2011;23:38. http://dx.doi.org/10.1186/2190-4715-23-38.

Stephenson GR, Ferris IG, Holland PT, Nordberg M. Glossary of terms relating to pesticides (IUPAC Recommendations 2006). Pure Appl Chem 2006;78:2075-154.

Struciński P, Góralczyk K, Ludwicki JK, Czaja K, Hernik A, Korcz W. Levels of selected organochlorine insecticides, polychlorinated biphenyls, phthalates and perfluorinated aliphatic substances in blood - Polish WWF study. Rocz Panstw Zakl Hig 2006;57: 99-112. [in Polish].

Toft G, Axmon A, Giwercman A, Thulstrup AM, Rignell-Hydbom A, Pedersen HS, et al. Fertility in four regions spanning large contrasts in serum levels of widespread persistent organochlorines: a cross-sectional study. Environ Health 2005;4:26. http://dx. doi.org/10.1186/1476-069X-4-26.

Vassiliadou I, Costopoulou D, Ferderigou A, Leondiadis L. Levels of perfluorooctanesulfonate (PFOS) and perfluorooctanoate (PFOA) in blood samples from different groups of adults living in Greece. Chemosphere 2010;80:1199-206. 